\title{
Analysis of hull resistance of pushed barges in shallow water
}

\author{
Tomasz Tabaczek \\ Jan Kulczyk \\ Maciej Zawiślak \\ Wrocław University of Technology
}

\begin{abstract}
These authors performed a set of numerical calculations of water flow around pushed barges differing to each other by bow forms. The calculations were executed by means of FLUENT computer software. Turbulent free-surface flow of viscous liquid was considered. In this paper the calculated values of barge hull resistance split into bow, cylindrical and stern part components, have been compared and presented.
\end{abstract}

Keywords : inland waterways ship, hull resistance

\section{INTRODUCTION}

The barges operating in push-train mode are characterized by great values of the hull block coefficients $\left(\mathrm{C}_{\mathrm{B}}>0.85\right)$, that ensures achieving large values of their displacement at assumed main dimensions. On the other hand, to decrease their building costs, usually is applied a simplified bow form consisted of practically developable surfaces divided by chine lines, thus relatively simple in building. Such approach is a rational and economical compromise since service speed of ships on inland waterways is of the order of $10-15 \mathrm{~km} / \mathrm{h}$.

An inspiration to undertake the research on hull resistance of inland navigation cargo ships has been given by the information coming from an inland navigation ship owner that the fuel consumption on a given shipping route differs significantly in the case of pushed barges differing to each other first of all by their bow forms. These authors decided to investigate which bow forms of pushed barges ensure obtaining the smallest hull resistance values. To this end several characteristic bow forms were selected [1]. Each of the selected characteristic forms has been adjusted to a barge having the main dimensions : $\mathrm{L}_{\mathrm{C}} \times \mathrm{B} \times \mathrm{T}=48.75 \times 9.0 \times 1.7 \mathrm{~m}$, under the assumption that the bow length from the end of the cylindrical midship body up to the bow transom plane is equal to $\mathrm{L}_{\mathrm{E}}=8.0 \mathrm{~m}$. Next, series of calculations of the flow around the push-trains consisted of two barges connected to each other by their stern parts, were performed. The calculations were executed by means of the FLUENT commercial computer software which makes it possible to take into consideration all factors of crucial influence on ship resistance, i.e. viscosity of water, turbulence of flow, as well as wave system on water free-surface around the ship.

Quality of the calculation results of free-surface water flow around inland navigation ships in shallow water, has been assessed during the previous research investigations carried out by these authors $[2,3]$. In view of a limited performance of the computers being at the authors' disposal most of the com- putations was performed for the hulls in a reduced scale. As a rule the same scale has been applied as in the case of model testing in a towing tank. A direct comparison of the results of the calculations with those from model tests has confirmed that the applied software is useful in calculating hull resistance and determining wave profile on the ship side.

\section{HULL FORMS OF THE CONSIDERED BARGES}

The calculations of water flow around hulls of the barges were performed for 11 trains of barges fitted with bows of the following forms (Fig.1) : EIIB, EIIBM, EIIBV2, EIIBH, ELI, ELIM, WALE, WALC, B, B3 and HEL. The first four constitute a group of similar forms. They have been elaborated on the basis of the hull form of the EUROPA IIb pushed barge popular on the West - European waterways. They differ to each other by the shape of longitudinal cross-section contour in the plane of symmetry. For the four barges similar results were achieved. The hull form of ELI barge has been elaborated on the basis of an elliptical bow (Ellipsenbug) proposed by Nussbaum [4]. The ELIM form is a simplified version of the ELI form. Rounded segments of frame sections have been replaced by straight-line segments inclined by the angle of $45^{\circ}$. As a result, the surface between the bottom and side of hull has become a developable surface. The WALE and WALC forms have vertical sides and are of the simplest geometry. They differ to each other only by a shape of water-planes which are elliptical in the first case, and in the other - circular segments tangent to ship sides. The B and B3 bow forms have been designed by the team working on the project. The form $\mathrm{B}$ ensures obtaining a high block coefficient value of the bow. Owing to the flat bottom it is possible to make the barge cubicoid hold much longer. The other bow form is more fine - it has a more inclined stem and higher elevated line of the side chine. The HEL bow form has been designed by these authors. Side surface of the bow 

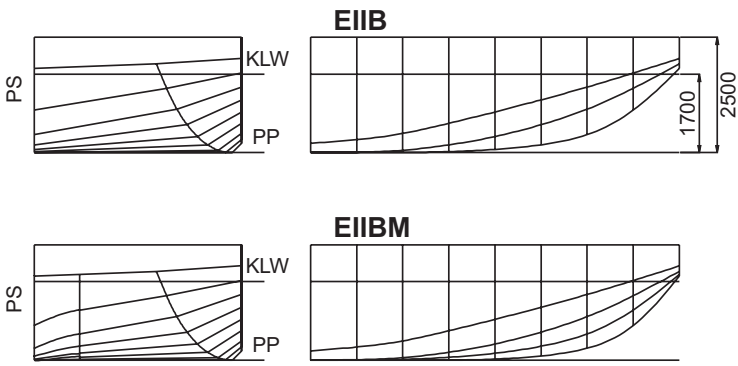

\section{EIIBM}
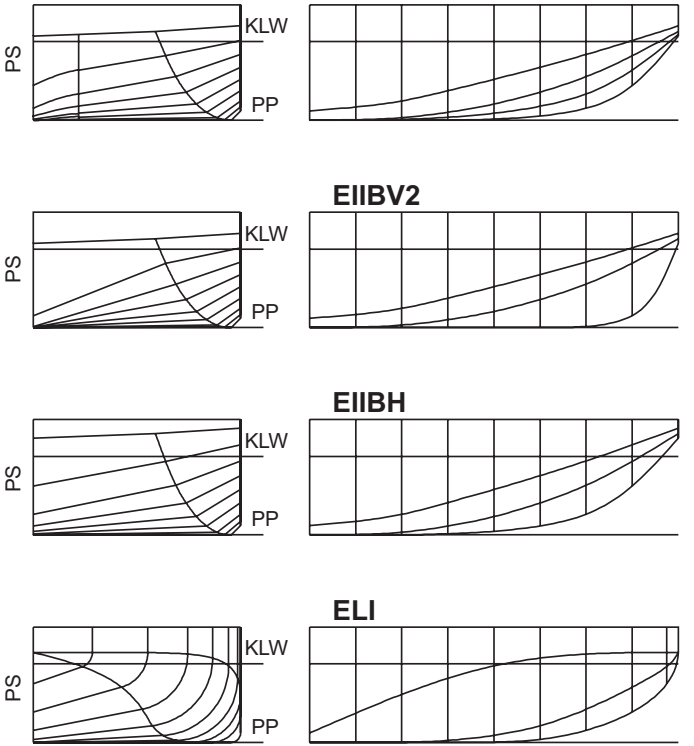

ELI
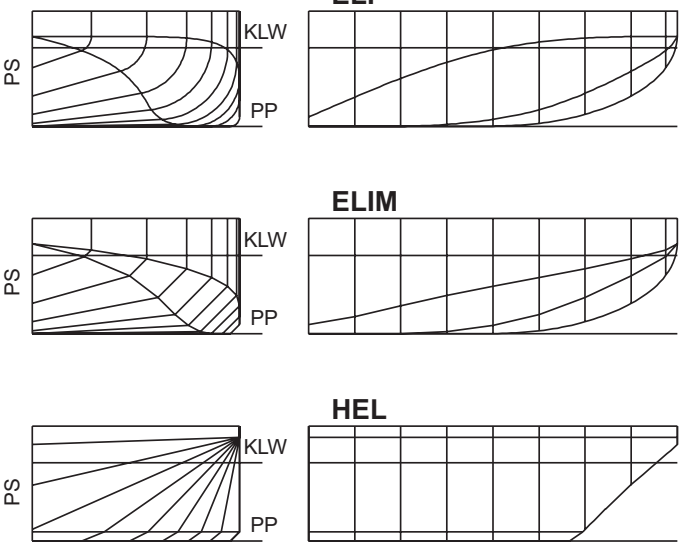
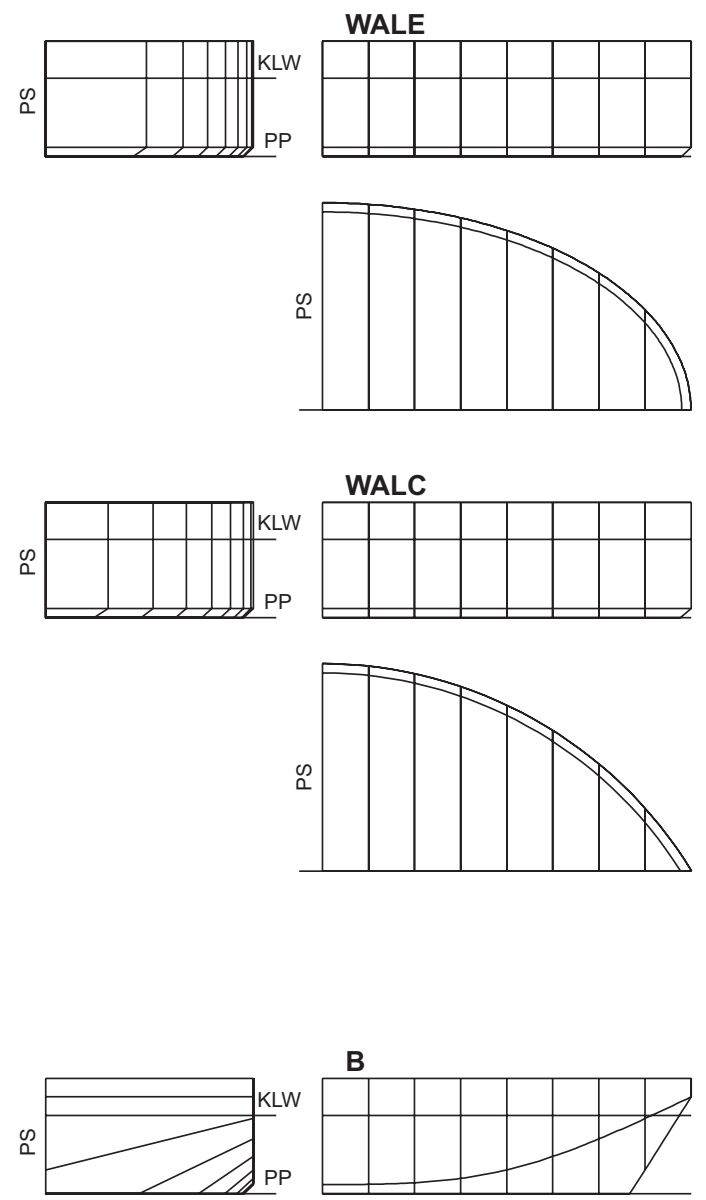

B

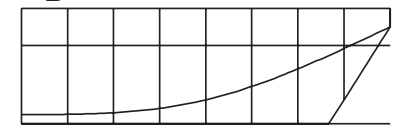

B3
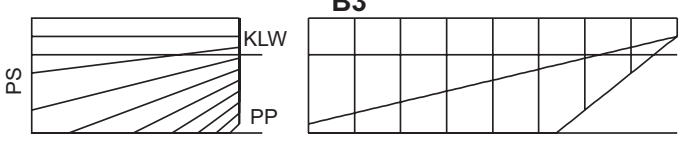

Fig. 1. Hull forms of the considered barges. PS - Plane of symmetry, PP - Base Plane, KLW - Design waterline .

is a fragment of a regular helicoid with its axis located in the plane of hull side. This shape was assumed to jostle water aside like the WALC form and simultaneously to integrate a broad deck and bow transom like in the case of the EIIB bow form. In the below presented table, are given values of the block coefficient of hull and that of bow which has been defined as follows : $\mathrm{C}_{\mathrm{BE}}=\mathrm{V}_{\mathrm{E}} /\left(\mathrm{L}_{\mathrm{E}} \times \mathrm{B} \times \mathrm{T}\right)$.

The authors have intended to check if any unambiguous relation between values of the above mentioned coefficients and hull resistance, takes place.

\begin{tabular}{|c|c|c|}
\hline Bow & $\mathbf{C}_{\mathbf{B}}$ & $\mathbf{C}_{\mathbf{B E}}$ \\
\hline EIIB & 0.952 & 0.705 \\
\hline EIIBM & 0.952 & 0.709 \\
\hline EIIBV2 & 0.956 & 0.742 \\
\hline EIIBH & 0.951 & 0.675 \\
\hline ELI & 0.950 & 0.695 \\
\hline ELIM & 0.949 & 0.699 \\
\hline WALE & 0.962 & 0.782 \\
\hline WALC & 0.949 & 0.700 \\
\hline B & 0.974 & 0.823 \\
\hline B3 & 0.952 & 0.663 \\
\hline HEL & 0.939 & 0.589 \\
\hline
\end{tabular}

The calculations were performed for the train of two barges connected to each other by their stern parts. To elaborate grids for numerical calculations the assumption was made that the stern form of a single barge influences train's resistance to the same degree, irrespective of an applied bow version. For this reason the aft bottom undercut was not modelled and the cylindrical parts of both barges were made longer and joined together in the aft transom plane.

The identical flat bilge form of $200 \mathrm{~mm}$ in height, was applied to all the barges, except of those having ELI bow form, where the cylindrical bilge form of $200 \mathrm{~mm}$ radius was used.

\section{CALCULATION CONDITIONS}

The flow calculations were performed for two values of water depth: $2.0 \mathrm{~m}$ and $3.4 \mathrm{~m}$. The first of them models the conditions of very shallow water $(\mathrm{h} / \mathrm{T}=1.18)$. In the case of canalised rivers such conditions appear only in certain places - along short sections of a waterway. The other water depth $(\mathrm{h}=3.4 \mathrm{~m})$ models shallow water conditions, which is more realistic for average service conditions on the domestic waterways.

In both the cases the calculations were carried out for the ship speed equal to $2.48 \mathrm{~m} / \mathrm{s}(8.93 \mathrm{~km} / \mathrm{h})$. i.e. at the Froude number $F n_{h}=0.56$ in a more shallower water, and $F n_{h}=0.43$ in a deeper water. At such speed a significant sagging of the ship should be taken into account, especially at the water depth equal to $2.0 \mathrm{~m}$. However the taking of sagging into account in calculations is associated with a change of location of bound- 
aries of computation area and a significant increase of time of computations. The authors have assumed that the neglecting of sagging introduces the same errors to resistance values of all the considered hull forms. Hence the differences in calculated resistance values would maintain the same, and to compare directly the bow forms would be possible.

For the calculations performed within the frame of this research work the authors made use of the same principles of building the computational grids and controlling calculation runs as those used in the previous research work [3].

All the calculations were performed in the model-scale of $1: 14$. The computational grid covered the rectangular area extending up to $41.25 \mathrm{~m}$ ahead the bow and behind the stern, and $45.5 \mathrm{~m}$ overboard. The grid mesh was so designed as to ensure precise modelling the hull form and the flow around hull surface. As a rule a regular grid consisted of cubicoid elements was applied, but irregular one - only locally. For the reason of a limited computer performance the number of elements did not exceed 200000.

In the FLUENT software the problem in question was defined as non-stationary one. The equations were integrated till reaching a stationary state. The applied time-step of $0.01 \mathrm{~s}$ ensured reaching the convergence of calculations after 30000 steps. To model the turbulence phenomenon the model RNG k- $\varepsilon$ was selected. A single run of calculations took $48 \mathrm{~h}$ on average.

\section{RESULTS}

In contrast to the experimental methods (towing tank model tests) the application of the numerical computation method to fluid mechanics (CFD) makes it possible to split hull resistance into the components resulting from normal stresses (pressure) and tangential stresses (liquid viscosity). It also makes it

\section{Total resistance}

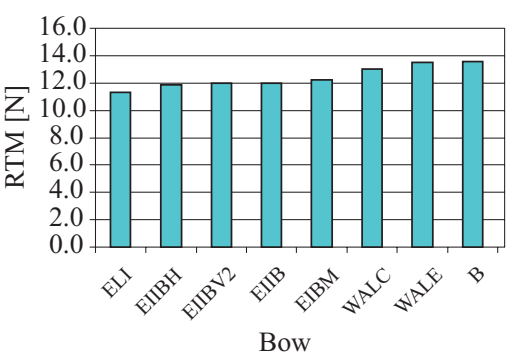

Pressure resistance

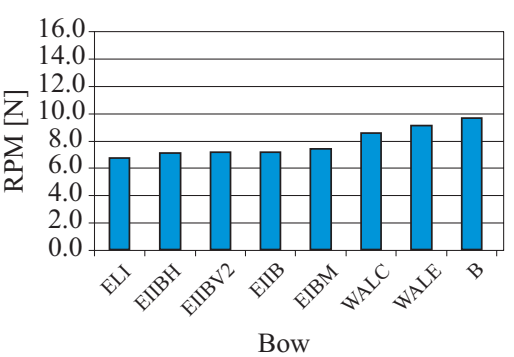

Viscosity resistance

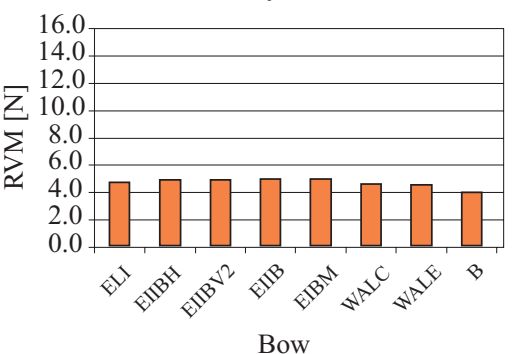

possible to easily determine forces acting on various parts of the hull. In order to analyse a contribution of particular hull segments in total hull resistance the authors split the entire hull surface into three parts :

* the bow (from the bow transom plane of fore barge to the cylindrical midship body)

* the cylindrical midship body (precisely - joined midship bodies of both fore and aft barges), and

* the stern (from the cylindrical midship body of aft barge to the bow transom plane of aft barge) (Fig.2).

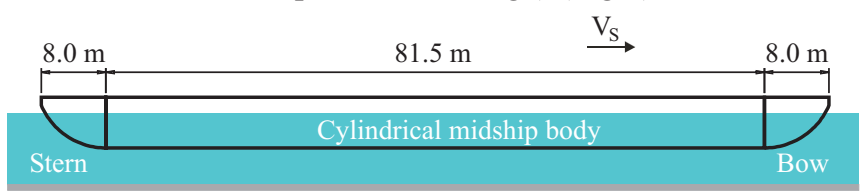

Fig. 2. The train of two barges split into three parts for resistance analysis purposes

The below presented values of hull resistance, calculated by means of the FLUENT software for free-surface flow conditions, take into account hydrostatic pressure.

In further considerations it was assumed that hull resistance is a force acting in the direction opposite to ship speed vector (i.e. aft). A negative value of stern resistance means that the resultant force acting onto the stern is directed fore. The greater the force the smaller the total hull resistance. In Fig. 3 and 4 the bow forms are ranked in a sequence resulting from increasing value of total resistance.

In design and service practice, quality of a pushed barge hull form is assessed by using the unit resistance values, $i$. e. those taken per unit buoyancy or volume of underwater part of ship's hull. The unit resistance values are compared in Fig. 5.

Bow resistance

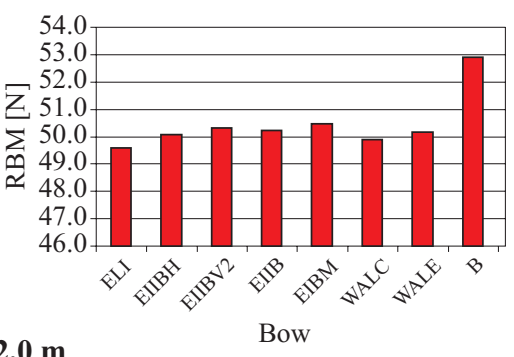

Midship body resistance

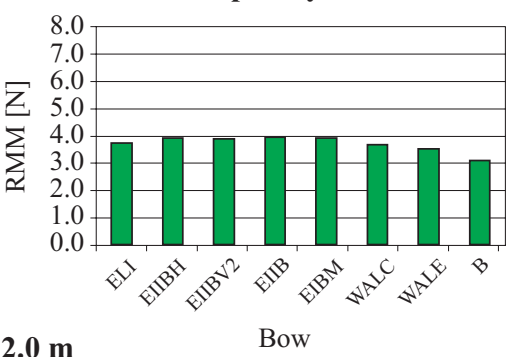

Stern resistance

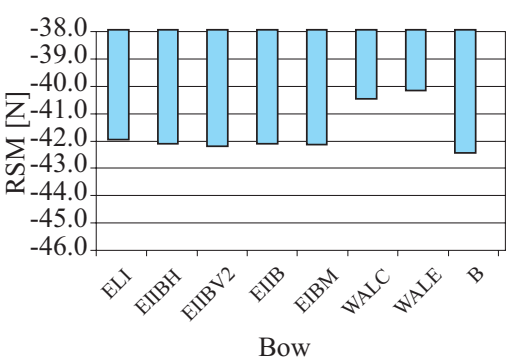

Fig. 3. Resistance of the two-barge-train model at the water depth of $2.0 \mathrm{~m}$. 
Total resistance

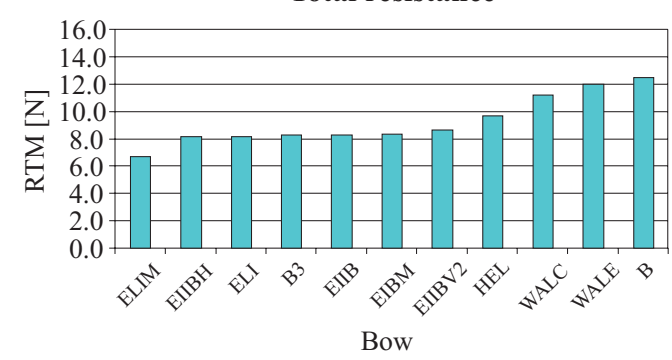

Bow

Pressure resistance

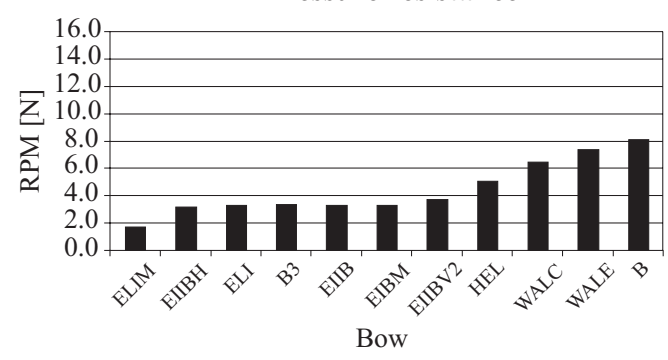

Viscosity resistance

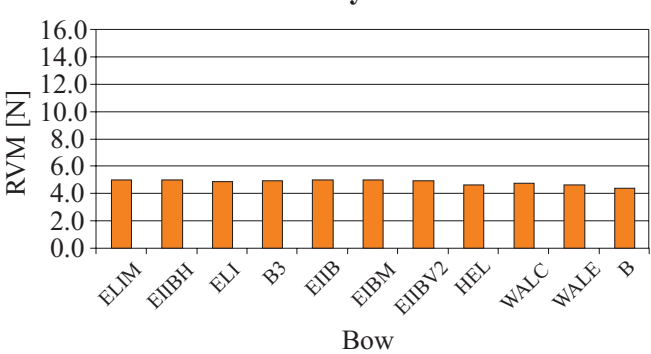

Bow resistance

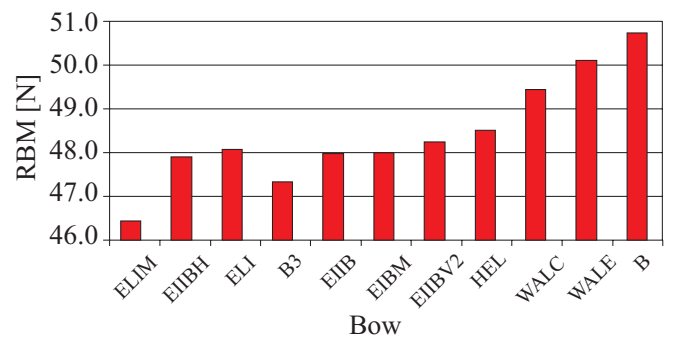

Midship body resistance

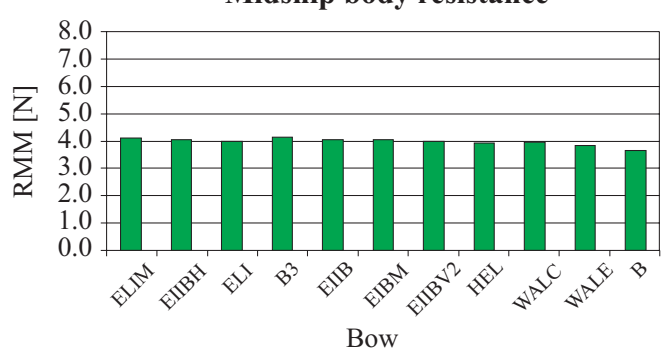

$h=3.4 \mathrm{~m}$

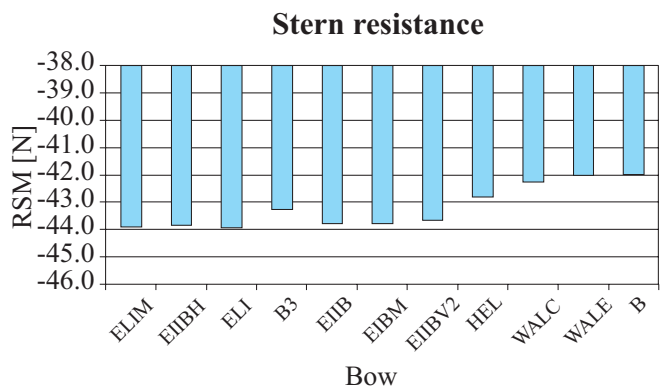

Fig. 4. Resistance of the two-barge-train model at the water depth of $3.4 \mathrm{~m}$.

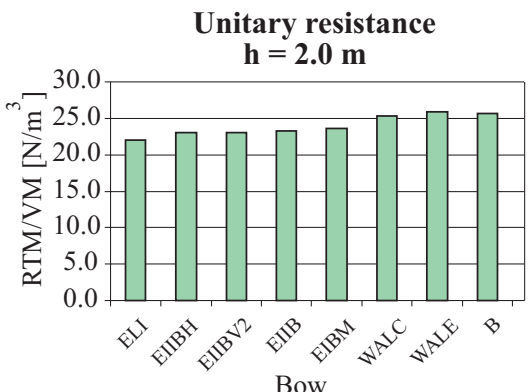

Unitary resistance

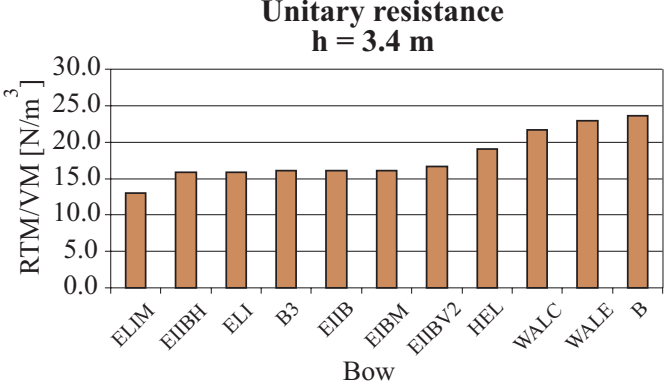

Fig. 5. The unit resistance values of the two-barge-train model.

\section{SUMMARY}

Onto the hulls jostling water aside (HEL, B, WALC, WALE) is exerted a greater pressure resistance and smaller viscosity resistance than onto the remaining hulls (Fig. 3 and 4).
However this is the pressure resistance which decides on the value of total resistance and ranking sequence of the bow forms. Also, onto those forms a greater aft pressure force and - simultaneously - a smaller fore resistance acts as a rule. These conclusions are also valid for full-scale ships since in this scale the share of pressure resistance in total resistance is greater than in the case of model-scale.

At the water depth $\mathrm{h}=3.4 \mathrm{~m}$ greater differences in hull resistance values occur than at the depth of $2.0 \mathrm{~m}$ (Fig.7), which means that though the resistance is smaller in the deeper water, this is the bow form which more influences the hull resistance.

In general, the hull and bow block coefficients constitute a rough index of quality of pushed barge hull resistance, but no unambiguous relation between those indices and hull resistance has been revealed (Fig. 6, 7, 8).

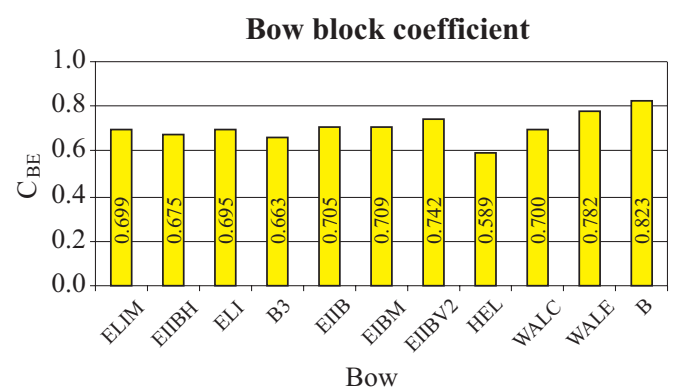

Fig. 6. The bow block coefficient $C_{B E}$ (the bows are ranked on the basis of their hull resistance values at the water depth of $3.4 \mathrm{~m}$, see Fig.4). 
In Fig. 7 and 8 the points are clustered in two groups. The bow forms : HEL, B, WALC and WALE belong to the first group, the remaining - to the other group. The bows of the first group have a straight, vertical or only slightly inclined stem, and greater resistance values as well. This observation suggests that the vertical or only slightly inclined stem is not favourable from the point of view of pushed barge hull resistance.
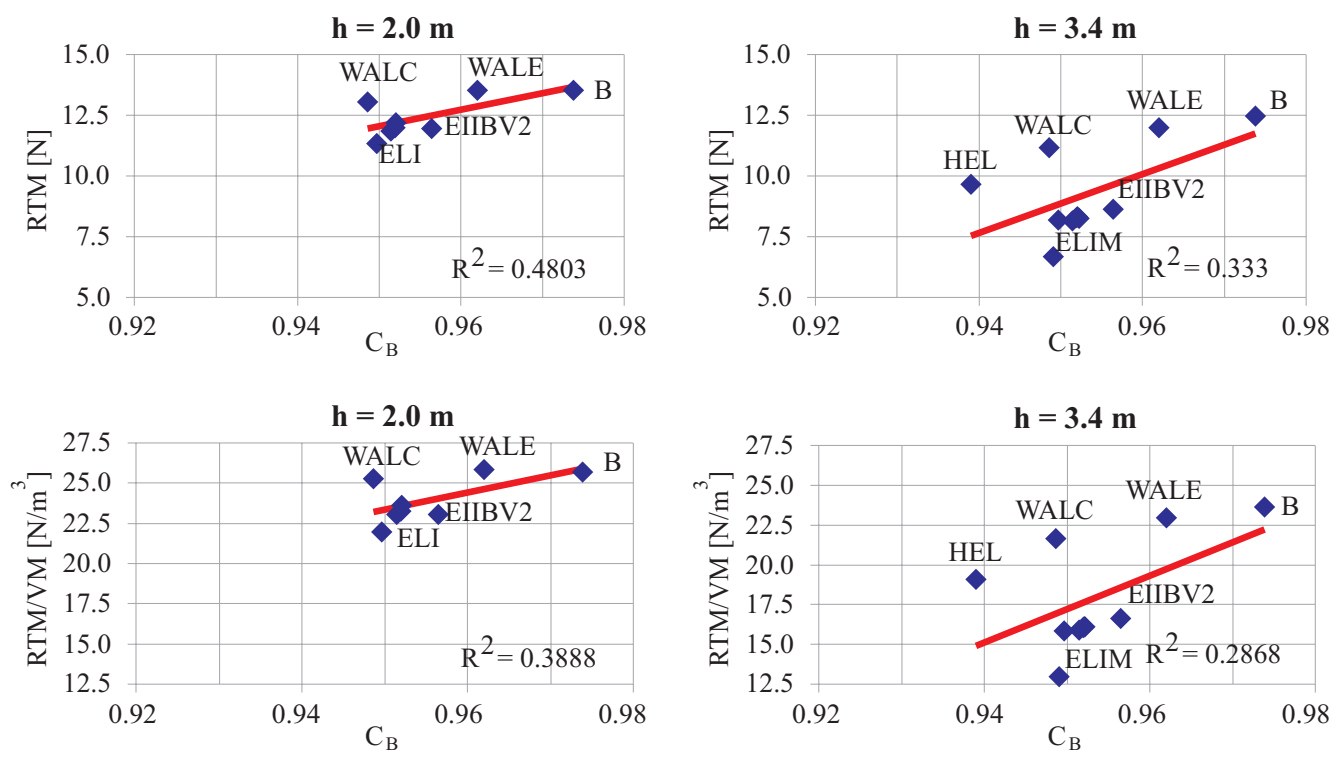

Fig. 7. The relationship of hull resistance and the hull block coefficient $C_{B}$.
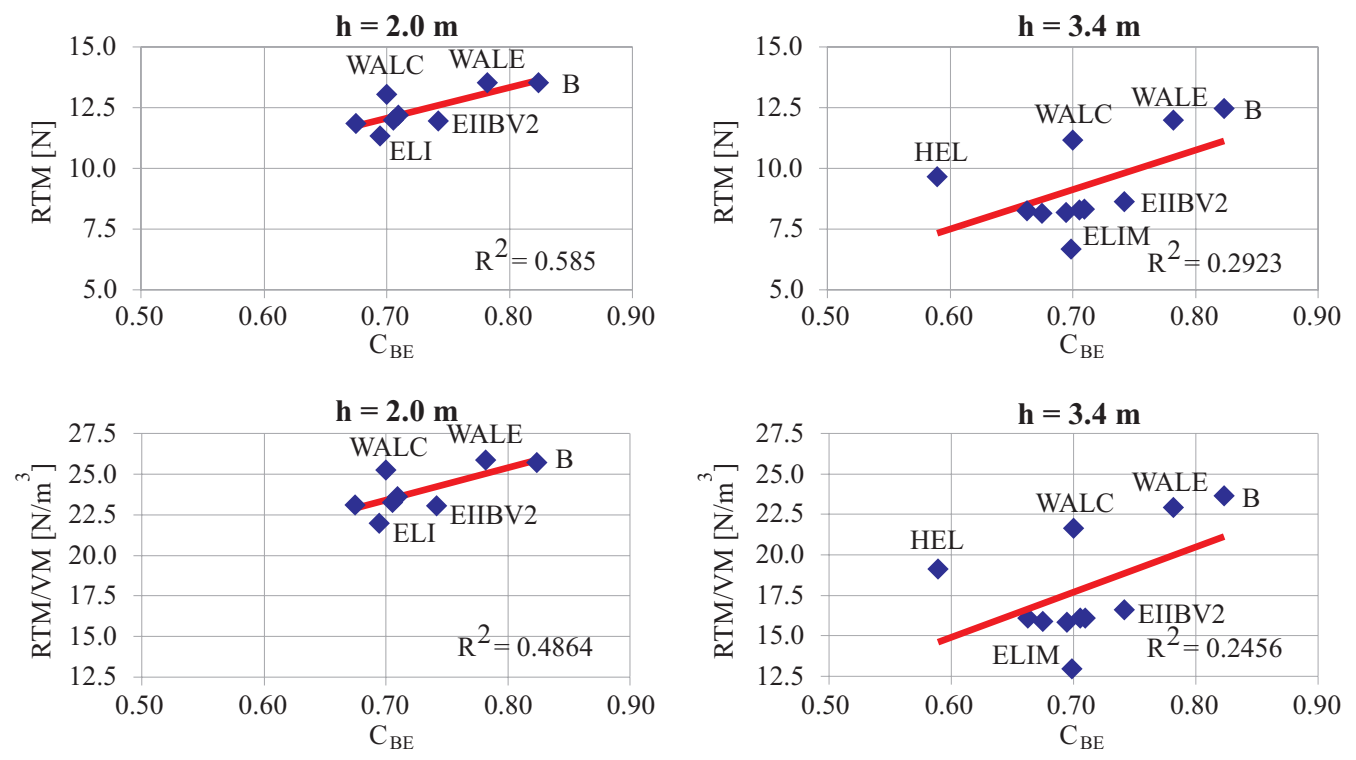

Fig. 8. The relationship of hull resistance and the bow block coefficient $C_{B E}$.

\section{NOMENCLATURE}

B - hull breadth

$\mathrm{C}_{\mathrm{B}}$ - hull block coefficient

$\mathrm{C}_{\mathrm{BE}}$ - bow block coefficient

$\mathrm{Fn}_{\mathrm{h}}$ - Froude number $\left(\mathrm{Fn}_{\mathrm{h}}=\mathrm{V}_{\mathrm{S}} / \sqrt{\mathrm{gh}}\right)$

g - gravity acceleration

h - water depth

$\mathrm{L}_{\mathrm{C}} \quad$ - overall length of ship

$\mathrm{L}_{\mathrm{E}}$ - length of bow

$\mathrm{T}$ - design draught

$\mathrm{V}_{\mathrm{E}}$ - bow volume

$\mathrm{V}_{\mathrm{EM}}^{\mathrm{E}}$ - bow volume in model-scale

VM - volume of hull underwater part in model-scale

$\mathrm{V}_{\mathrm{S}}$ - ship speed

RBM - bow resistance in model-scale

RPM - pressure resistance in model-scale

RSM - stern resistance in model-scale

RTM - total resistance in model-scale
RVM - viscosity resistance in model-scale

RMM - resistance of cylindrical midship body in model-scale

\section{Acknowledgement}

The research presented in this paper has been financially supported by the Minister for Science and Informatics, within the frame of the research project No. 4 T12C 01427.

\section{BIBLIOGRAPHY}

1. Kulczyk J., Tabaczek T., Werszko R., Zawiślak M., Zieliński A.: Bow forms of inland navigation cargo vessels. 16th International Conference on Hydrodynamics in Ship Design HYDRONAV'05. Gdańsk-Ostróda, Poland. 7-10 September 2005

2. Zawiślak, M., Tabaczek, T.: Resistance prediction by using CFD. Report T32-PWR-IREP-Resistance prediction CFD of research project INBAT within 6. Outline Program (G3RD-CT-2001-0458). August 2004 
3. Zawiślak, M.: Influence of waterway depth on pressure resistance of inland navigation ship (in Polish). Doctoral thesis. Report of Preprint Series No. PRE 028/04, Institute of Machine Building and Operation, Wrocław University of Technology. Wrocław, 2004

4. Nussbaum, W.: Entwicklungen der Binnenschiffsformgebung unter Berücksichtigung der Anforderungen im Flachwasserseegang, Jahrbuch der STG, Bd 82, 1988

\section{CONTACT WITH THE AUTHORS}

Tomasz Tabaczek, D.Sc., Eng. Prof. Jan Kulczyk

Maciej Zawiślak, D.Sc., Eng.

Institute of Machine Design and Operation,

Wrocław University of Technology Łukasiewicza 7/9

50-371 Wrocław, POLAND

e-mail : tomasz.tabaczek@pwr.wroc.pl

\section{Conference \\ HYDROACOUSTICS 2006}

On 23 - 26 May 2006

at Krynica Morska upon Vistula Bay was held :

\section{$13^{\text {th }}$ SYMPOSIUM ON HYDROACOUSTICS}

organized by the Department of Marine Electronic Systems, Faculty of Electronics, Telecommunication and Informatics, Gdańsk University of Technology, under the auspices of : European Acoustics Association, Hydro-acoustics Section of Committee on Acoustics, Polish Academy of Sciences, and Gdańsk Division of Polish Acoustical Society.

The Symposium was commenced by the key-note lecture on :

Research and development on underwater acoustic systems of Polish Naval University and Gdańsk University of Technology for the Polish Navy - by G. Grelowska (Polish Naval University) and L. Kilian (Gdańsk University of Technology).

During 4 plenary session of the Symposium the following 5 invited papers were presented :

- Science and technology in Polish Ministry of Defense by W. Drag (Polish Ministry of Defense)

$\rightarrow$ New scientific multi-beam systems for fishery research applications - by L. Nonboe (SIMRAD, Norway)

- The state of the Baltic Sea hydro-acoustical investigations (selected problems) - by Z. Klusek (Institute of Oceanology, Polish Academy of Sciences)

- Synthesis and wavelet analysis of side-scan sonar sea bottom imagery - by J. Tęgowski (Institute of Oceanology, Polish Academy of Sciences) and A. Zieliński (University of Victoria, Canada)

- Quadrature phase detection in an acoustic positioning system - by A. Zieliński (University of Victoria, Canada) and Y.Shi (Southwest Jiaotong University, China)

The remaining 25 papers were presented during 4 panel sessions. Original papers, both theoretical and experimental, concerning problems of hydro-acoustics and its applications are published in the annual journal Hydro-acoustics.

\section{(coustics.}

\section{Workshops 2006}

Under this name, on 30 March $\div 1$ April 2006, Faculty of Maritime Technology, Technical University of Szczecin, arranged the series of popular scientific lectures and demonstrations to promote the courses on

\section{Ocean Engineering and Transport} conducted at the Faculty.

Academic lecturers presented the following themes :

$\star$ Safety at sea - by M. Hann

* Gas an oil mining from sea bed by W. Chądzyński

$\star$ Contemporary maritime industry and shipping - by T. Jastrzębski

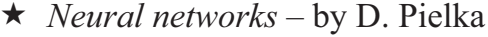

$\star$ Shapes of sound - by S. Weyna

$\star$ Super-computers and turbulence by T. Abramowski

$\star$ Unconventional energy sources on ships by W. Zeńczak

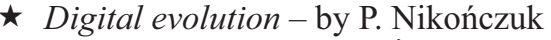

$\star$ Stirling's engine - by A. Żmuda

The last day the underwater apparatuses built at the Faculty were demonstrated. The Workshops appeared very interesting for many visitors hence it was decided to organize them every year. 